\title{
Post Abortion Choice and Acceptance of Contraception
}

\author{
Shrestha A, ${ }^{1}$ Sharma $\mathbf{P}^{2}$ \\ ${ }^{1}$ Department of General Practice and Emergency Medicine, ${ }^{2}$ Department of Obstetrics and Gynaecology, \\ Patan Academy of Health Sciences (PAHS), Patan, Nepal.
}

\begin{abstract}
Aims: This study was conducted to find out choice and acceptance of contraceptives in clients coming for first trimester abortion.
Methods: This was a cross sectional descriptive study carried out from the records of clients who received comprehensive abortion care service in first trimester at Kasthamandap health care centre from June 2008 to June 2010.

Results: Total 707 clients came for abortion who fulfilled inclusion criteria. Contraceptive acceptance was $49.5 \%$. Most frequently used contraceptives were injectable (depot medroxyprogesterone) $22.8 \%$, oral contraceptive pills $19.6 \%$, condom $6.1 \%$, intra-uterine contraceptive device $0.8 \%$ and norplant $0.3 \%$.
\end{abstract}

Conclusions: This study showed a low acceptance rate of contraception. This suggests the need for reviewing the policy of post abortion contraception. The study also highlighted that depot provera was the most accepted contraception.

Keywords: contraception acceptance, contraception choice, post abortion contraception.

\section{INTRODUCTION}

Annually out of the 205 million pregnancies around 80 million unwanted pregnancies occur worldwide, of these 42 million are terminated, 22 million legally and 20 million illegally. ${ }^{1}$ In developing country, most of the unwanted pregnancies are due to the non-use or the inconsistent use of contraceptive methods. ${ }^{2,3}$

All women should receive counseling and family planning service after any abortion, such promotion is one of the most effective strategies to reduce abortion rate and maternal morbidity and mortality. ${ }^{4}$ Contraceptive counseling could result in an increase of method compliance and motivate the use of family planning methods. ${ }^{5}$

\section{CORRESPONDENCE}

Dr Ashis Shrestha

Department of General Practice and Emergency Medicine, Patan Academy of Health Sciences, Patan, Nepal.

Email: ashis_ktm@yahoo.com

Phone: $9851 \overline{0} 61846$
The objective of this study was to describe the acceptance and the choice of contraceptive method in post abortion cases in the one of the registered comprehensive abortion care centre in Kathmandu, Nepal.

\section{METHODS}

A cross sectional study was carried out by going through the records of clients who received comprehensive abortion care service from July 2008 to July 2010 at Kasthamandap Health Care Centre. Nepal government's official record register supplied to this centre was used to extract the records. Institutional approval was taken. The clients with complete record and who gave consent were included in the study. Data was analyzed using SPSS 16.0.

The papers in this journal are published under the terms of the Creative Commons Attribution License. Users are allowed to read, download, copy, distribute, print, search, or link to the full texts of the articles in this journal without asking prior permission from the publisher or the author. 


\section{RESULTS}

Total 707 clients came for first trimester abortion and all of them were included in the study. Among them 616 (87.1\%) clients were from Kathmandu district while 91 (12.9\%) were from other districts. The contraceptive acceptance was seen in 350 (49.5\%) clients. Acceptance rate of different contraceptives are shown in the bar chart below (Figure 1).

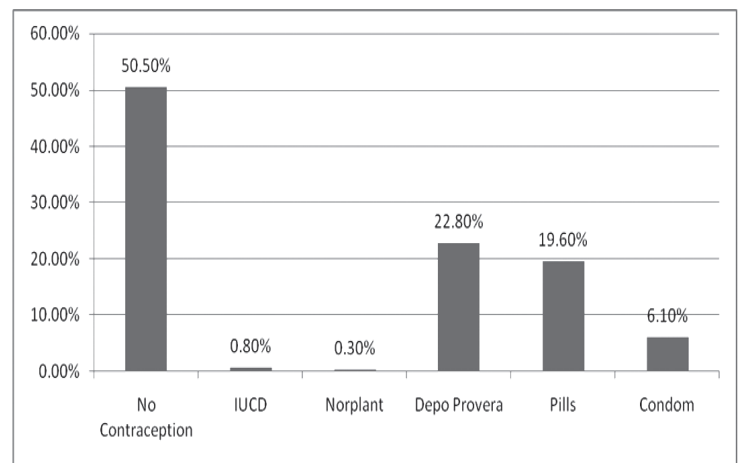

Figure 1. Frequency distribution showing acceptance of diferent contraceptions.

Amongst the various ethnic groups, 317 (45\%) were from upper caste group, 279 (38.3\%) were from disadvantaged janajati, 85 (11.9\%) were from relatively advantaged janajatis, 19 (2.5\%) were from dalits, 10 (1.4\%) were from disadvantaged non-dalit and $6(0.8 \%)$ were from religious minority group. Contraceptive acceptance was 9 (44\%), $38(44 \%) 130(48 \%), 3(50 \%), 165$ (52\%), 6 (60\%), in dalit, relatively advantaged janajati, disadvantaged janajatis, religious minorities, upper caste group and disadvantaged non-dalit respectively. Similarly variation of contraceptive choice in different ethnic groups is given below (Figure 2).

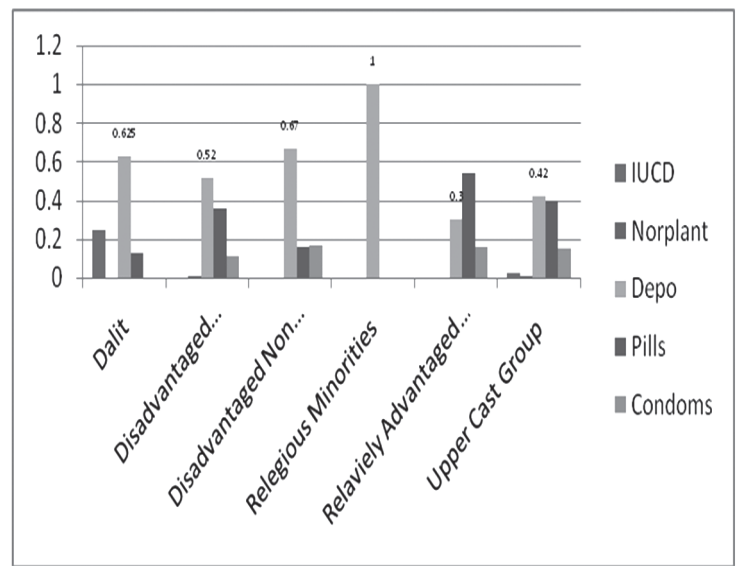

Figure 2. Proportion of contraception choice in different ethinic group $(p=0.09)$.
Out of 707 clients $39.3 \%$ were from the age group 20-25 years, followed by $22.8 \%$ from $25-30$ years, $22.8 \%$ from 15 20 years, $10.5 \%$ from $30-35$ years, $3.7 \%$ from $35-40$ years and $1.0 \%$ from $40-45$ years. Contraceptive acceptance in different age groups were 113 (41\%), 90 (56\%), 78 (49\%), 31 (43\%), 12 (61\%) and $3(57 \%)$ respectively as above mentioned age group (Figure 3).

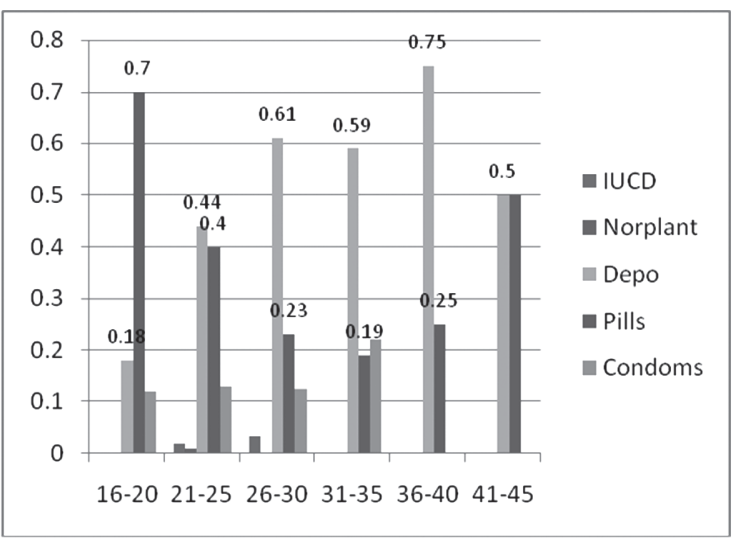

Figure 3. Proportion of contraception choice in different age group $(p<0.05)$.

Out of 707 clients 351 (49.8\%) had education above SLC level, 146 (20.5\%) were under SLC and 210 (29.7\%) were illiterate. Contraceptive acceptance was 183 (52\%), (53\%) and $90(42 \%)$ respectively in above mentioned education level (Figure 4).

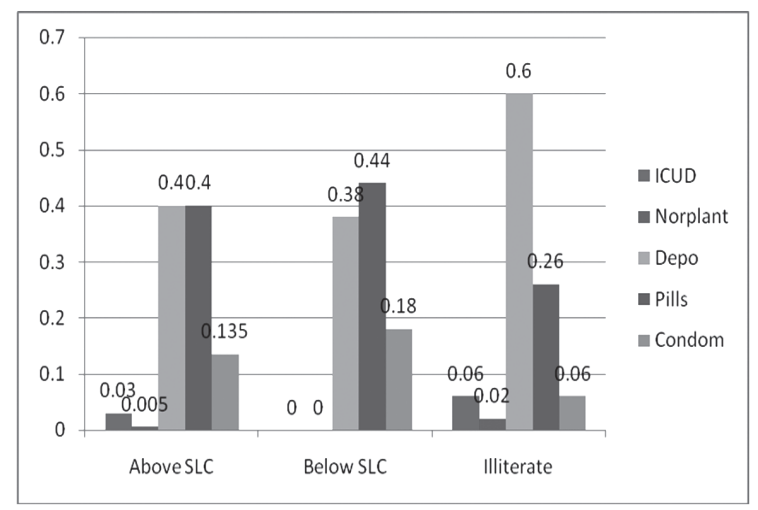

Figure 4. Proportion of contraception choice with level of education $(p=0.05)$.

Out of all clients receiving abortion care 355 (52.2\%) were in week six of gestation, 129 (19.7\%) in week seven of gestation, 91 (13.2\%) in week eight of gestation and $132(19.9 \%)$ in other weeks of gestation. A total of 337 (47.4\%) were primipara, 353 (50.5\%) multipara, and 17 (2.1\%) were grand-multipara. Contraceptive acceptance was $44 \%, 55 \%$ and $4 \%$ in primipara, multipara and grand multipara respectively (Figure 5). 


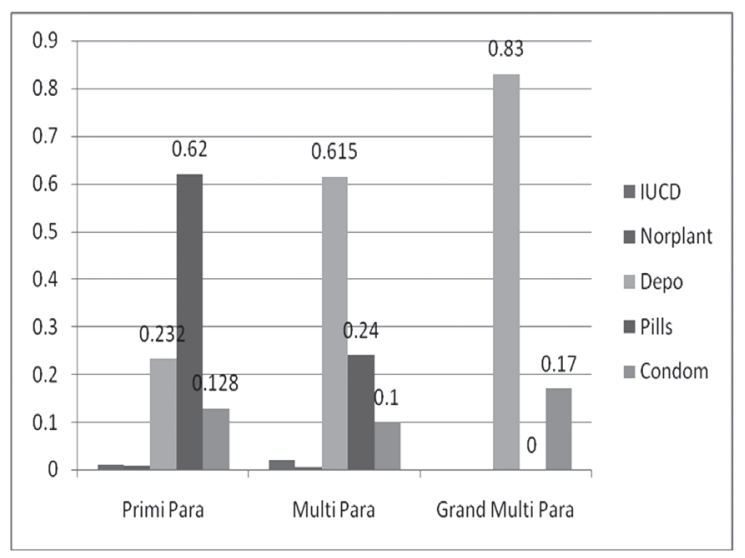

Figure 5. Proportion of contraception choice with parity $(p<0.05)$.

\section{DISCUSSION}

The contraceptive acceptance in our study was $49.5 \%$ which is very low in comparison to the post abortion contraception acceptance rate in other part of world. A paper published from Tanzania stated their post abortion contraceptive acceptance rate as $89 \% .{ }^{6}$ Likewise, it was $97.4 \%$ in a cross sectional study published from Brazil in $2008 .^{7}$ The acceptance and continuation of contraception is highly influenced by level of information given, one-toone counseling, satisfaction with services, and shorter travel time to source. ${ }^{8}$

Among those who have accepted contraceptive, depot provera use was the highest $(22.8 \%)$ followed by oral contraceptive pills (19.6\%) and others. A randomized trial concluded that most chosen method was injectables, followed by oral contraceptives. ${ }^{9}$ We have limited evidence about what works to help clients choose an appropriate contraceptive method. However, communication part has been focused much. One trial showed audiovisual aids worked better than the usual oral presentation. Strategies for communicating information should be examined in clinical settings and assessed for effect on contraceptive choice and retention of knowledge. ${ }^{10}$

Contraception acceptance was marginally more in disadvantaged non-dalits. The most popular contraceptive was depot provera followed by oral contraceptive pills. The choice of contraception varies according to ethnicity in other part of world as well, in a study trying to determine the explanatory variables regarding ethnic differences in contraceptive use, only two of the proposed factors were found to play a significant role. These two factors were level of comfort with sexual communication and perceived convenience of contraception. These two variables were shown to provide an indirect path between ethnicity and contraceptive use. ${ }^{11}$
The contraceptive acceptance rate was the highest in age group 36 to 40 years (61\%) and the lowest in age group 16 to 20 years (41\%). The choice of contraception was depot provera in all age groups followed by oral contraceptive pills. However, in the age group 16-20 years, choice of contraception was oral contraceptive pills followed by depot provera. The difference observed between each group on various contraception was statistically significant $(p<0.05)$. Early age of women was as an important factor for decreased contraceptive acceptance in a study from Shanghai. This is the age where clients are usually unmarried or newly married. Unmarried women prefer family planning services that protect their privacy, where they can be anonymous, and use service providers they trust. $^{12}$

Contraceptive use is strongly associated with women's education. ${ }^{13}$ Contraceptive acceptance rate was higher in educated group (above SLC 52\%, below SLC 53\%) than uneducated (42\%). The preferred choice of contraception for the uneducated group was depot provera and educated group chose oral contraceptive pills followed by depot provera. The difference observed between each groups on various contraception was statistically significant ( $p=$ 0.05).

Most of the clients using contraceptives were multipara (55\%). The choice for primipara was oral contraceptive pills. Most of the multipara chose depot provera. The difference observed between each groups was statistically significant $(p<0.05)$. A study analyzing on the selection of a model suggested that there were four independent major factors affecting the use and nonuse of contraception: number of living children, frequency of exposure to mass media, level of education, and current age. There also was a relationship among the following factors: age with number of living children and number of living children with level of education. Although experience of abortion did not affect contraceptive use, it was strongly associated with age. Among these four factors, education had the strongest effect, followed by number of living children. ${ }^{14}$

Improving contraceptive counseling and training for midwives and physicians, increasing contraceptive choices, and promoting access to contraceptives on site may reduce women's risk of unwanted pregnancy and, potentially, unsafe abortion. ${ }^{15}$

\section{CONCLUSIONS}

This study showed a low acceptance rate of contraception. Young age and low level of education had been seen as major factors for decreased acceptance of contraception. It also highlighted depot provera as choice of contraceptive in all age groups except in young age where choice of contraceptive was oral contraceptive pills. Post abortion contraception should be utilized as an effective measure 
of contraception. This is an opportunity to increase the rate of contraceptive acceptance to decrease unwanted pregnancies. This was a small study so a larger study is needed.

\section{REFERENCES}

1. Sedgh G, Henshaw S, Sing S, Ahman E, Shah IH. Induced abortion: estimated rates and trends worldwide. Lancet. 2007;370:1338-45.

2. Kero A, Högberg U, Lalos A. Contraceptive risk-taking in women and men facing legal abortion. Eur J Contracept Reprod Health Care. 2001;6(4):205-18.

3. Rash V, Massawe S, Yambesi F, Bergstrom S. Acceptance of contraceptives among women who had an unsafe abortion in Dar es Salaam. Trop Med Int Health. 2004;9(3):399-405.

4. Rash V, Yambesi F, Massawe S. Medium and long term adherence to post abortion contraception among women having experienced unsafe induced abortion in Tanzania. BMC Pregnancy Childbirth. 2008;32:1-8.

5. Weisman CS, Maccannon DS, Henderson JT, Shortridge $\mathrm{E}$, Orso CL. Contraceptive counseling in managed care: preventing unintended pregnancy in adults. Womens Health Issues. 2002;2(2):79-95.

6. Ferreira A, Souza A, Lima R, Braga C. Choices on contraceptive methods in post-abortion family planning clinic in the northeast Brazil. Reproductive Health. 2010;7:5.

7. Ferreira AL, Lemos A, Figueiroa JN, de Souza. Effectiveness of contraceptive counselling of women following an abortion: a systematic review and meta-analysis. Eur J Contracept Reprod Health Care. 2009;14(1):1-9.
8. Gubhaju B. Barriers to sustained use of contraception in Nepal: quality of care, socioecomomic status and method related factors. Biodemography Soc Biol. 2009;55(1):52-70.

9. Schunmann C, Glasier A. Specialist contraceptive counselling and provision after termination of pregnancy improves uptake of long-acting methods but does not prevent repeat abortion: a randomized trial. Hum Reprod. 2006;21(9):2296303.

10. Lopez LM, Steiner M, Grimes DA, Schulz KF. Strategies for communicating contraceptive effectiveness. Cochrane database syst rev. 2013 Apr 30;4:CD006964. doi: 10.1002/14651858.CD006964.pub3.

11. Christman $S$, Zawackio T. Understanding ethnic disparities in contraceptive use. URJHS. [Online] 2009;Vol 8. Available from: http://www.kon.org/urc/v8/christman.html [Accessed 10th June 2013].

12. Qian $X$, Smith $H$, Huang $W$, Zhang J, Ying $H$, Garner $P$. Promoting contraceptive use among unmarried female migrants in one factory in Sanghai: a pilot workplace intervention. BMC Health Services Research. 2007;7:77.

13. Saleem S, Bobak M. Women's autonomy, education and contraception use in Pakistan: a national study. Reproductive Health. 2005;2:8.

14. Utomo B, Alimoeso S, Park CB. Factors affecting use and non use of contraception. Majalah Demografi Indones.1983;10(20):19-48.

15. McDougall J, Fetters T, Clark KA, Rathavy T. Determinents of contraceptive acceptance among Combodian abortion patient. Stud Fam Plann. 2009;40(2):123. 